\title{
RESEARCH ON THE END-GAME EFFECT IN THE IMPLEMENTATION OF REGIONAL ECONOMIC PLANNING -AN EMPIRICAL STUDY BASED ON SUB-PROVINCIAL CITIES
}

\author{
Zhan-Bing Huang \\ International Business School, Shaanxi Normal University, Xi'an 710119, P. R.China \\ Ying Liu* \\ International Business School, Shaanxi Normal University, Xi'an 710119, P. R.China \\ Shan $\mathrm{Wu}$ \\ International Business School, Shaanxi Normal University, Xi'an 710119, P. R.China
}

\begin{abstract}
Is there end-game effect in the implementation of regional economic planning? According to the game theory, there is no difference between the final game and the one-time game when approaching the end of the game. The participant's non-cooperative behavior will not be punished, so the dominant strategy of the participant in the last phase is noncooperation. Then will the deadline of the planning lead to the end-game effect of the implementer in the implementation of regional planning? Through the construction of mixed model of panel data, integrating the existing research on the influencing factors of investment in fixed assets, we choose data selected from 2006 to 2015 (Eleventh and Twelfth Five-Year Plan) of fifteen sub-provincial cities in China to examine whether exists end-game effect in the implementation of the planning. The results support our hypothesis-it indeed exist end-game effect in the implementation of regional economic planning. This study provides new ideas and methods for the sustainable development of regional economy.
\end{abstract}

Keywords: end-game effect; planning period; the growth rate of investment in fixed assets

JEL code: $\mathrm{C} 7, \mathrm{O} 2$

\section{Introduction}

Many repeated linear public goods laboratory experiments showed that backwards induction-based contributions are substantially more generous than expected zero Nash equilibrium contributions. ${ }^{1}$ However, these experiments showed that individuals interacting in a finite rounds contribution game often start out by contributing substantial amounts that decline as the number of rounds increases, and reach their minimum towards the end of the game. This is called the "end-game effect" (see Andreoni 1988).

In terms of regional economic planning, scholars have been focusing on the problems in the planning and implementation, and generally studied from the four perspectives of regional planning objectives, planning contents, planning procedures and planning management ( $\mathrm{Li}$

\footnotetext{
${ }^{1}$ See Ledyard (1995) and Chaudhui (2011) for survey of public goods experimental research. See also Wilhelm, Brown, Rooney and Steinberg (2008) for empirical evidence on intergenerational transmission generosity.
} 
Guangbin,2006) and put forward relevant policies or suggestions for improvement. Fang Chuanglin (2001) analyzes the reasons why the effect of the planning is not significant from the perspective of the six pathologies in the development and implementation of China's regional planning. There are hardly any studies from the perspective of the planning period of regional economic planning. We chooses the 11th Five-Year Plan and the 12th Five-Year Plan of fifteen sub-provincial cities in China, and find that the planning period has a certain influence on its implementation effect: when the deadline of the planning is approaching, the growth rate of investment in fixed assets will show a significant downward trend, which will affect the effect of the implementation of the planning, thus leading to miscarriage with the planning finally. Testing the end-game effect existing in the planning from the new perspective of planning period can provide new ideas and ways for future development of China's regional economic planning.

\section{Literature Review}

At present, scholars at home and abroad mainly study the end-game effect from the perspective of standard economics and behavioral economics.

The study of the end-game effect under the standard economics is based on the premise of the "complete rational economic man". The participants can make the optimal decision to maximize their own interests at every stage through backward induction, realizing the sub-game perfect Nash equilibrium prediction finally (Luis G. Gonzoález, Wener Güth, M. Vittoria Levati , 2005). However, behavioral economics' research on the end-game effect is based on the assumption of "bounded rationality", which is embodied in the fact that people will cheat at the end to avoid regret. It is mainly explained from the following four aspects: Scarcity and Anticipatory Regret, Moral Self-Licensing, Ego-Depletion, Slippery Slope (Daniel A. Effron, Christopher J. Bryan, \& J. Keith Murnighan, 2015). Life is full of opportunities to commit ethical violations for personal gain; often, these opportunities come in a series with a known end. When people face ethical quandaries in which they must choose whether to increase their own outcomes by cheating or to preserve a desirable self-concept by upholding their moral obligations. Our study found cheating will be most likely at the end(Daniel A. Effron, Christopher J. Bryan.2015).The deadline did have an effect on humans' behavior.

The regional economic planning is referred to the strategic planning and industrial development and layout of the regional economic development, the overall plan for the future economic construction (Cui Gingham, 1999). The existing research on this issue mainly discusses from the perspective of the political tournament system. Zhou Li'an (2004) referred to this kind of official promotion incentive system as political tournaments. Lazear and Rosen (1981) first revealed the incentive role of the tournament system and refined it into an incentive mechanism by considering incentives for both risk-neutral participants. And the scholar Nordhaus (1975) first proposed the "political business cycle theory", the government would show great confidence and determination to develop the economy after they took office. New party and state leaders put forward new goals, formulate new economic plans, develop new economic policies and set off new economic upsurge, which have a significant effect on the economic expansion. Tao yifeng $(2004)$ found that the bank would easy credit during the Communist Party Congress since 1987, the four peaks of the growth rate of total fixed asset investment respectively appear in the following year of the 13th,14th,15th,16th National Congress of CPC. 
In summary, scholars have barely studied from the perspective of planning period. In view of this, we take the 11th Five-Year Plan and the 12th Five-Year Plan of 15 sub-provincial cities in China as the research sample; establish a mixed model of panel data to test the existence of end-game effect.

\section{Theoretical basis}

The reputation model of Kreps, Milgram, Roberts, and Wilson (Kreps, Milgrom, Roberts and Wilson, 1982) demonstrates that participants 'incomplete information on other participants' payment functions or strategic spaces has a significant impact on the equilibrium outcome. As long as the number of repetitions of the game is long enough, the cooperative behavior will be achieved in a limited number of repetitive games. However the game subject will change the strategy and choose not to cooperate once he is told that it is the final period.

In the regional economic planning with definite deadline, we can find that the implementer of the planning will choose not to cooperate in the final period through the repeated game between the planner and implementer of the planning. As shown in the table below, there is a game with two participants (planner, implementer of the planning), where $\mathrm{p}<0<\mathrm{m}<\mathrm{n}$.

Table 1 the payoff matrix of the two participants

\begin{tabular}{ccc}
\hline Planner Implementer & Cooperation & Noncooperation \\
\hline Cooperation & $\mathrm{m}, \mathrm{m}$ & $\mathrm{P}, \mathrm{n}$ \\
Noncooperation & $\mathrm{n}, \mathrm{p}$ & 0,0 \\
\hline
\end{tabular}

The planner and the implementer can choose cooperation or non-cooperation. If you choose to cooperate, both gets $\mathrm{m}$; if you choose not to cooperate, then both gets 0 ; if one cooperate, another not to cooperate, getting $\mathrm{p}$ and $\mathrm{n}$ respectively.

Standard game theory is based on the hypothesis of "complete rationality" to analyze how participants can achieve equilibrium while pursuing their optimal goals. If the game is one-time game, the optimal choice of the participants is noncooperation, meanwhile achieving the only Nash equilibrium (noncooperation, noncooperation), the income of both $(0,0)$. In order to avoid the greatest loss, or get the maximum benefit, in a one-time game, non-cooperation is the best choice for both sides.

However, the reality is that everyone is "bounded rationality", if the game is repeated T times, a new equilibrium may be obtained. It is assumed that there are two kinds of planners, one is completely rational and can be called "opportunist" or non-cooperative participant; the other is not completely rational, and its irrational probability is $a$, rational probability is (1-a). It is assumed that the game starts from $t=0$, repeats $t=T$ times and the behavioral strategy of the non-rational rational subject is "tit for tat". Each participant knows that he is rational or irrational, but does not know each other's situation.

At the beginning, if both are rational, then the noncooperation is the optional choice and it will continue, the outcome of both is 0 . If the planner is rational, the implementer is irrational, then the planner will choose noncooperation $(t=0)$, and the implementer choose cooperation, and then the implementer will take "tit for tat" strategy and choose noncooperation. Thus, at 
the end of the 1 game, the total revenue of the planner is at most $n$ ( $n$ is obtained at $t=0$ and 0 at $\mathrm{t}=1,2,3)$.

Now we consider another strategy for the planner: choosing to cooperate until $\mathrm{T}$, unless the implementer chooses noncooperation at a period of $t$ (at this time, the planner will choose noncooperation from $t+1$ to $T$ ). In this case, if the other is irrational, the both will continue to cooperate, the income of planner is $\mathrm{m}(\mathrm{T}+1)$; if the other is completely rational, the income of planner is at worst $\mathrm{p}$. The expected return from this strategy is:

$$
a[m(T+1)]+(1-a) p
$$

No matter how small a, we can always find a $\mathrm{T}$ that makes

$$
a[m(T+1)]+(1-a) p>n
$$

It can be seen that, for planner, even if he is completely rational, it is not optimal to choose noncooperation in period 0 . It means that as long as the planning period is long enough, the optional choice for both sides is cooperation. At the very beginning, both want to establish a trustworthy, cooperative reputation in order to get long-term expected return from cooperation. But no matter how long the game is, in terms of the regional economic planning, the game cannot be indefinite, there is a length of time, there is a deadline for the planning. Then when near the end of the planning, the implementer realizes that it is the final period, it is possible to pay more attention to the current interests, giving up the accumulative income over the past few short-term behavior, reducing investment in order to obtain the largest short-term gains, which is the so-called "end-game effect".

According to above analysis, we put forward the view that there is end-game effect in the planning with definite terminating period.

\section{Empirical test}

\subsection{Research methods and data sources.}

(1) Variable selection and definition

The investment in fixed assets is caused by various social and economic factors. According to the economic theory and the actual situation of 15 sub-provincial cities, we choose the growth rate of fixed asset investment to study the end-game effect in regional economic planning. Integrating existing research on the factors affecting the investment of fixed assets by many scholars(Song Lizhi,2011;Liu Xiaoxia,2005),we choose the growth rate of GDP, fiscal expenditure and total retail sales of social consumer goods as explanatory variables. The growth rate of investment in fixed assets is the explained variable. In addition, because each regional economic plan has a definite five-year planning period, in order to illustrate the existence of the end-game effect, we introduce dummy variables into the model, the fifth year to take 1 , the first four years to take 0 .

A total of 150 samples of 15 sub-provincial cities from 2006 to 2015 were selected as the object of the study. Since the samples were small, the explanations and tests were difficult, so the original data of each variable was divided by the price index of corresponding year, excluding the impact of inflation.

\subsection{Empirical analysis}

\section{(1) Unit root test of panel data}


In order to guarantee the robustness of the test results, the unit root test of the data is the first important step. We use the LLC test for the same root, which is applicable to four kinds of methods, such as IPS test, ADF - Fisher test and PP - Fisher test. y represents growth rate of fixed asset investment, $x 1$ represents growth rate of GDP), $x 2$ represents the growth rate of fiscal expenditure, $\mathrm{x} 3$ represents the growth rate of total retail sales of social consumer goods.

Table2 unit root test results

\begin{tabular}{|c|c|c|c|c|c|}
\hline variable & LLC test & IPS test & ADF-Fisher test & PP-Fisher test & Stationary test \\
\hline $\mathrm{Y}$ & $\begin{array}{c}-9.53096 \\
(0.0000)\end{array}$ & $\begin{array}{c}-1.29668 \\
(0.0974)\end{array}$ & $\begin{array}{r}52.7488 \\
(0.0063)\end{array}$ & $\begin{array}{c}65.8012 \\
(0.0002)\end{array}$ & stationary \\
\hline $\mathrm{X} 1$ & $\begin{array}{l}-4.58727 \\
(0.0000)\end{array}$ & - & $\begin{array}{c}47.0458 \\
(0.0246)\end{array}$ & $\begin{array}{c}68.7690 \\
(0.0001)\end{array}$ & stationary \\
\hline $\mathrm{X} 2$ & $\begin{array}{l}-7.55578 \\
(0.0000)\end{array}$ & $\begin{array}{r}-1.37152 \\
(0.0851)\end{array}$ & $\begin{array}{c}54.9704 \\
(0.0036)\end{array}$ & $\begin{array}{c}101.080 \\
(0.0000)\end{array}$ & stationary \\
\hline $\mathrm{X} 3$ & $\begin{array}{l}-11.9826 \\
(0.0000)\end{array}$ & $\begin{array}{r}-2.14172 \\
(0.0161)\end{array}$ & $\begin{array}{c}67.1858 \\
(0.0001)\end{array}$ & $\begin{array}{c}75.9174 \\
(0.0000)\end{array}$ & stationary \\
\hline
\end{tabular}

According to the results of Table1,we can find that whether the growth rate of fixed asset investment, GDP, fiscal expenditure or total retail sales of social consumer goods, the P-value all pass the significant test, that is, the whole sequence is stationary.

\section{(2) Co-integration test}

From the results of unit root test in Table1, we can find that each variable has a long-term equilibrium trend. That is, there is a co-integration relationship. In order to further explore the possible linear combination among the variables, the co-integration test is carried out as following:

\begin{tabular}{cccc}
\hline & Table3 & co-integration test between variables y,x1, x2, x3 & \\
\hline Testing method & Statistics & Statistical value & P-value \\
\hline Kao test & ADF & -3.423284 & 0.0003 \\
& Panel v-Statistic & -1.122703 & 0.8692 \\
& Panel rho-Statistic & 1.997441 & 0.9771 \\
Pedroni & Panel PP-Statistic & -3.294018 & 0.0005 \\
& Panel ADF-Statistic & -2.382933 & 0.0086 \\
& Group rho-Statistic & 3.445522 & 0.9997 \\
& Group PP-Statistic & -7.321291 & 0.0000 \\
& Group ADF-Statistic & -3.678957 & 0.0001 \\
\hline
\end{tabular}

According to Table2, the accompanying probability P-values of Panel PP-Statistic, Panel AD-Statistic, Group PP-Statistic, Group ADF-Statistic were less than 0.01, and the original hypothesis was rejected at the $1 \%$ significance level, so there is a co-integration relationship between the variables. The probability of Kao test is 0.0003 , which also rejects the original hypothesis at the $1 \%$ significance level, and further supports the conclusion that there is a panel co-integration relationship between the variables. 
(3) the identification and establishment of model F test

Table4 F test of Panel data model

\begin{tabular}{ccccc}
\hline Testing method & Statistics & Statistical value & Degrees of freedom & P-value \\
\hline $\begin{array}{c}\text { Redundant fixed } \\
\text { effects test }\end{array}$ & $\mathrm{F}$ & 0.884068 & $(14,131)$ & 0.5775 \\
\hline
\end{tabular}

As can be seen from Table $3, \mathrm{~F}$ test with the probability of $\mathrm{P}$-value is greater than 0.05 , so accepting the original hypothesis. Namely, we should select the mixed effect model, thus not having to continue Hausman test.

\section{Model settings}

Based on the above test, the model is a mixed effect model, and the model is given as follows: $Y_{\text {it }}=\mathrm{a}+X_{\text {it }} \beta+U_{\text {it }}, \mathrm{t}=1,2, \ldots \mathrm{T} ; \mathrm{i}=1,2, \ldots, \mathrm{N}$

\section{The regression results}

$$
\begin{aligned}
& Y_{\text {it }}=0.4098 G D P_{\text {it }}+0.2243 C Z_{\text {it }}+0.5286^{X F_{\text {it }}}-0.037 D_{\text {it }} \\
& \mathrm{T}=(1.6688) \quad(2.1105) \quad(2.6794) \quad(-1.68) \\
& \mathrm{P}=(0.0973) \quad(0.0365) \quad(0.0082) \quad(0.0951) \\
& R^{2}=0.2953 \quad \text { S.E }=0.1108
\end{aligned}
$$

From the above results, we can see that the symbol of the coefficients of GDP, fiscal expenditure and the total retail sales of social consumer goods is consistent with the reality, which shows that the result is in line with economic theory. The P-value of the $t$ statistics is $0.0973,0.0365,0.0082,0.0951$, all of which is less than 0.1 , indicating that the estimated value of the parameter is statistically significant.

The dummy variable reflects the hypothesis to be tested. The result estimated by the model suggests that the coefficient in front of the dummy variable is negative, indicating that the growth rate of the fixed assets investment in the last year is decreased by $3.7 \%$ than in the previous four years and its accompanying probability P-value is significant at the level of 0.1.In short, there exists obvious end-game effect in the implementation of the regional economic planning.

\section{Conclusions}

So far, no scholars have focused on the issue that the definite planning period has an effect on the implementation of regional economic planning. We selected the data of 11th Five-Year Plan and the 12th Five-Year Plan of 15 sub-provincial cities to establish a mixed effect model and found that the deadline of termination has a significant effect on the implementation of the planning. Compared with the previous four years, the growth rate of fixed asset investment in the last year fell down $3.7 \%$, from which we can conclude that there is end-game effect in the implementation of the planning with a definite termination period.

The new perspective can provide new ideas for the declining effect of the implementation of the planning, and then provide a new way to the development of regional economy. However, how to solve the end-game effect existing in the regional economic planning via taking concrete measures, making the effect of the planning improve and regional cooperation and development continue with a steady level, is of greater importance. We leave these issues for 
future research.

\section{References}

Chen Yiqing Shi Qi. Game Analysis on the Phenomenon of 59-year-old in the Management of State-owned Enterprises [J] .Enterprise economy, 2004, (01): 36-37.

Chaudhuri, A.Sopher, B.,\& Strand, P. (2002). Cooperation in social dilemmas, trust, and reciprocity. Journal of Economic Psychology, 23, 231-249.

Cochard, F., Van, P.N., \& Willinger, M. (2004). Trusting behavior in a repeated investment game. Journal of Economic Behavior \& Organization, 55 (1), 31-44.

Daniel A. Effron, Christopher J. Bryan. Cheating at the End to Avoid Regret. Journal of Personality and Social Psychology. 2015, Vol. 109, No. 3, 395-414.

Huang Wendi. From the limited repetitive game experiments show that human behavior can lead to diversity outcome [J]. China's collective economy, 2016, (22): 75-76.

Hong Lei. Game Analysis of Fifty-nine-year-old.[J]. World Economic Situation, 2007, (02): $72-75$.

Li Guangbin, Wang Xi, Wang Yong. Study on the Problems and Countermeasures of Regional Planning in China [J]. Journal of Geographical Research and Development, 2006,25 (5): 1013.

Li Guangbin, Wang Yong, Gu Renxu. Study on the Development and Implementation of Regional Planning in China [J]. Geography and Geo-Information Science, 2006, (06): 48-53.

Liu Xiaoxia. China's fixed asset investment changes in the characteristics and influencing factors [J]. Statistics and decision-making, 2005, (17): 81-82.

Luis G. González, Wener Güth, M. Vittoria Levati When does the game end? Public goods experiments with non-definite and non-commonly known time horizons. Economics Letters 88 (2005) 221-226

Ma Na, Liu Shilin. Regional planning implementation effect evaluation index system construction research [J]. Regional Economic Review, 2015, (04): 20-23.

Qiao Kunyuan. Tournament mechanism for Chinese officials' promotion: theory and evidence.[J]. Economic Science, 2013, (01): 88-98.

Qiao Kunyuan. Re-examination on the tournament mechanism for Chinese officials' promotion-evidence from the provincial and municipal governments.[J]. Finance and Economics, 2013, (04): 123-133.

Ren Guihua. The economic mechanism behind the "59-year-old phenomenon".[J]. Management modernization, 2000, (03): 18-19.

Ronen Bar-El, Yossef Tobol, Contribution Games and the End-Game Effect: When Things 
Get Real - An Experimental Analysis. Discussion Paper No. 7307, 2013 (3)

Song Lizhi. China's fixed asset investment and economic growth relationship between the re-test: 1980 - 2010 [J]. Macroeconomic Research, 2011, (11): 17-21 + 46.

Tang Zhijun, Xiang Guocheng, Chen Ying. Study on the Issue of Corruption of Promotion Championships and Local Government Officials [J] .Shanghai Economic Research, 2013, (04): 3-14 + 38 .

Wang Jiangang. Research on Incentive System of Promotion Championship.[D].Southwest University of Political Science and Law, 2014.

Wang Lili, He Qiang, Li Fen. An Empirical Analysis of Factors Affecting Social Fixed Assets Investment.[J]. Contemporary Economy, 2011, (18): 142-143.

$\mathrm{Yu}$ XuPeng. Officials' promotion championships: political logic of economic growthcombing and analyzing based on related literature [J]. East China Economic Management, 2016, (06): 88-95.

Zhou Yi Ren. Thoughts and Suggestions on the Problems of Regional Planning in China during the Eleventh Five-Year Plan Period.[J]. Regional Research and Development, 2005,24 (3): $1-5$.

Zhang Weiying. Game Theory and Information Economics.[M]. Shanghai: Gezhi Publishing House .hanghai People's Publishing House, 2012. 